\title{
Increased inflammatory markers in the exhaled breath condensate of cigarette smokers
}

\author{
G.E. Carpagnano*, S.A. Kharitonov\#, M.P. Foschino-Barbaro", O. Resta*, E. Gramiccioni”, P.J. Barnes ${ }^{\#}$
}

Increased inflammatory markers in the exhaled breath condensate of cigarette smokers. G.E. Carpagnano, S.A. Kharitonov, M.P. Foschino-Barbaro, O. Resta, E. Gramiccioni, P.J. Barnes. (C) ERS Journals Ltd 2003.

ABSTRACT: Cigarette smoking induces an inflammatory response in the airways that may play a key role in the pathogenesis of chronic obstructive pulmonary disease. Noninvasive markers of inflammation may, therefore, be useful in monitoring the airways of smokers as well as in the screening of subjects at high risk of developing airway obstruction.

The aim of the present study was to determine whether the concentrations of the proinflammatory cytokine, interleukin (IL)-6, is increased in the exhaled breath condensate of smokers and whether the number of cigarettes smoked has any influence on the exhaled concentrations. The possibility that exhaled IL-6 levels are related to exhaled carbon monoxide (CO) and lung function has also been explored. Another inflammatory marker, leukotriene (LT), was also measured.

Twenty-one smokers (39 \pm 7 yrs, 13 male) and 14 nonsmokers (45 \pm 6 yrs, eight male) were recruited. IL-6 and $\mathrm{LTB}_{4}$ levels in the breath condensate were measured with an immunoassay kit and exhaled $\mathrm{CO}$ examined by means of a modified electrochemical sensor. Higher IL-6 and exhaled CO concentrations were found in current smokers $\left(5.6 \pm 1.4 \mathrm{pg} \cdot \mathrm{mL}^{-1}\right.$ and $16.7 \pm 5.5$ parts per million $\left.(\mathrm{ppm})\right)$ than in nonsmokers $(2.6 \pm$ $0.2 \mathrm{pg} \cdot \mathrm{mL}^{-1}$ and $\left.2.1 \pm 0.6 \mathrm{ppm}\right)$. Elevated concentrations of $\mathrm{LTB}_{4}$ were also observed in smokers compared to nonsmokers $\left(9.4 \pm 0.4 \mathrm{pg} \cdot \mathrm{mL}^{-1}\right.$ versus $\left.6.1 \pm 0.3 \mathrm{pg} \cdot \mathrm{mL}^{-1}\right)$. In addition, there was a correlation between IL-6 concentrations, the number of cigarettes smoked per day, exhaled $\mathrm{CO}, \mathrm{LTB}_{4}$ and lung function.

Exhaled interleukin-6 and leukotriene $B_{4}$ levels may be useful noninvasive markers of airway inflammation in cigarette smokers.

Eur Respir J 2003; 21: 589-593.
*Institute of Respiratory Disease, University of Bari, Italy. ${ }^{\#}$ Dept of Thoracic Medicine, National Heart and Lung Institute, Imperial College Faculty of Medicine, London, UK. Institute of Respiratory Disease, University of Foggia, Italy.

Correspondence: P.J. Barnes

Dept of Thoracic Medicine

National Heart and Lung Institute

Dovehouse Street

London

SW3 6LY

UK

Fax: 442073515675

E-mail: p.j.barnes@ic.ac.uk

Keywords: Airway inflammation

carbon monoxide

interleukin-6

leukotriene $\mathrm{B}_{4}$

smokers

Received: March 192002

Accepted after revision: December 202002
Cigarette smoking is associated with neutrophilic inflammation of the airways which, in $15-20 \%$ of cases, is followed by the obstruction of the small airways [1]. Several studies have demonstrated that chronic obstructive pulmonary disease (COPD) is associated with an inflammatory process that takes place in the peripheral airways [2]. However, the mechanism by which the inflammation causes airway obstruction remains unknown [3].

An increased number of neutrophils in the airways has been found in cigarette smokers and this is related to the number of cigarettes smoked [4]. The profile of pro-inflammatory cytokines measured in bronchoalveolar lavage (BAL) is also related to the number of cigarettes smoked [5].

Interleukin (IL)-6 is a pro-inflammatory cytokine produced by epithelial cells and macrophages in the airways [5, 6]. Increased concentrations of IL-6 have been found in the BAL [5] and the induced sputum of smokers [7]. These invasive methods do not allow frequent monitoring of the inflammatory response [8].

The aim of present study was to measure IL-6 levels in smokers using a completely noninvasive method, the exhaled breath condensate. To exclude a possible salivary contamination of the breath condensate, measurements of this cytokine in saliva were also taken. Leukotriene $(\mathrm{LT}) \mathrm{B}_{4}$ was also measured in the exhaled breath condensate in some of the subjects, as this is another marker of inflammation and has previously been shown to be elevated in induced sputum of smokers [9]. Any correlation between IL-6 in the exhaled breath condensate, number of cigarettes smoked, lung function, $\mathrm{LTB}_{4}$ and exhaled carbon monoxide $(\mathrm{CO})$, was also evaluated. Exploring the mechanisms underlying the inflammatory process and cigarette smoking may be useful in understanding the pathogenesis of inflammation in COPD and may uncover the predisposition to develop airway obstruction in smokers.

\section{Material and methods}

\section{Study population}

The study population consisted of 21 smokers (13 male, $39 \pm 7 \mathrm{yrs}$, forced expiratory volume in one second (FEV1) $104 \pm 4 \%$ predicted, forced vital capacity (FVC) $107 \pm 6 \%$ pred, carbon monoxide diffusing capacity of the lung ( $D \mathrm{~L}, \mathrm{CO})$ $100 \pm 2 \%$ pred and $D \mathrm{~L}, \mathrm{CO}$ corrected for alveolar volume (carbon monoxide transfer coefficient (KCO)) $101 \pm 3 \%$ pred) with normal lung function (defined as a FEV $1>80 \%$ pred) and 14 age-matched healthy nonsmokers ( 8 male, $45 \pm 6$ yrs, FEV1 $101 \pm 18 \%$ pred, FVC $119 \pm 9 \%$ pred, $D$ L,CO $102 \pm 3 \%$ pred and KCO $105 \pm 4 \%$ pred). All of the subjects were recruited by the Respiratory Disease Institute of the University of Bari (Italy) and written informed consent was obtained from them all. The study was approved by the Institutional Ethics Committee. 
Smokers (all of them for $\geqslant 10 \mathrm{yrs}$ ), were divided into three subgroups: subjects who smoked $<1$ pack $\cdot$ day $^{-1}(\mathrm{n}=7)$, subjects who smoked 1 pack $\cdot$ day $^{-1}(\mathrm{n}=7)$ and subjects who smoked $>1$ pack $\cdot$ day $^{-1}(\mathrm{n}=7)$.

All subjects were also characterised with methacholine challenge and measurement of $D \mathrm{~L}, \mathrm{CO}$, taken to exclude those with asthma or emphysema. None of the subjects showed any bronchoconstriction in response to the methacholine challenge (the provocative concentration of methacholine giving a $20 \%$ fall in FEV1 $\left.(\mathrm{PC} 20)>16 \mathrm{mg} \cdot \mathrm{mL}^{-1}\right)$ or any impairment in diffusing capacity.

None of the subjects presented any symptoms of lower respiratory tract infection (dyspnoea, cough and/or purulent sputum) for $\geqslant 3$ months prior to enrolment. The exclusion criteria for the study were as follows: 1) antimicrobial treatment during the previous 4 weeks; 2) treatment with oral corticosteroids in the previous 3 months; 3) hospital admission during the previous 3 months; and 4) the presence of any severe comorbidities (e.g. severe immunosuppression, malignancies and coagulopathies).

\section{Study design}

This study was designed to assess whether the concentrations of IL- 6 and $\mathrm{LTB}_{4}$ were increased in the exhaled breath condensate of smokers and whether the number of cigarettes smoked had any influence on the exhaled concentrations.

\section{Pulmonary function testing}

Pulmonary function tests were performed $\leqslant 1$ day of the measurement of the breath condensate. FEV1, FVC and the FEV1/FVC ratio were measured using a spirometer (PK Morgan Ltd, Gillingham, UK).

Measures of diffusing capacity $(D \mathrm{~L}, \mathrm{CO}, \mathrm{KCO})$ were performed by a single-breath technique (Transfer Factor; Erich Jaeger, Wurtzburg, Germany). The best value of three procedures was expressed as a percentage of the predicted normal value.

\section{Methacholine challenge}

A series of methacholine chloride solutions were prepared, ranging from $0.05-25 \mathrm{mg} \cdot \mathrm{mL}^{-1}$. These solutions were prepared in doubling concentration intervals, with $2 \mathrm{~mL}$ of each dilution being administrated by a nebuliser. After inhalation of the aerosol, FEV1 was measured at 1, 3, 5 and $10 \mathrm{~min}$, and the concentration was increased by one step until a $20 \%$ drop in FEV1. PC20 was then determined by interpolation.

\section{Exhaled breath condensate}

The exhaled breath condensate was collected by using a condenser, which permitted noninvasive collection of the nongaseous components of the expiratory air (EcoScreen; Jaeger, Wurzburg, Germany). The subjects breathed through a mouthpiece and a two-way nonrebreathing valve, which also served as a saliva trap. They were asked to breathe at a normal frequency and tidal volume, wearing a noseclip, for $10 \mathrm{~min}$. If the subjects salivated they were instructed to swallow. The condensate, $\geqslant 1 \mathrm{~mL}$, was collected as ice at $-20^{\circ} \mathrm{C}$, transferred to Eppendorf tubes and immediately stored at $-70^{\circ} \mathrm{C}$.

\section{Measurement of interleukin-6}

A specific enzyme immunoassay kit (Cayman Chemical, Ann Arbor, MI, USA) was used to measure IL-6 concentrations in the breath condensate. The assay was validated directly by gas chromatography/mass spectrometry. The intra-assay and inter-assay variability were $\leqslant 10 \%$. The detection limit of the assay was $1.5 \mathrm{pg} \cdot \mathrm{mL}^{-1}$.

\section{Measurement of leukotriene $B_{4}$}

A specific enzyme immunoassay kit (Cayman Chemical) was used to measure $\mathrm{LTB}_{4}$ concentrations in breath condensate of 10 smokers and 10 healthy controls. The intra-assay and inter-assay variability were $<10 \%$. The specificity was $100 \%$ and the detection limit of the assay was $3 \mathrm{pg} \cdot \mathrm{mL}^{-1}$.

\section{Measurement of exhaled carbon monoxide}

Exhaled CO was measured using a modified electrochemical sensor with sensitivity from 1 part per million (ppm) to $500 \mathrm{ppm}$ of $\mathrm{CO}$. Measurement of $\mathrm{CO}$ was carried out by a LR2000 chemiluminescence analyser (Logan Research Ltd, Rochester, UK) using an external resistance of $0.40 \pm 0.05 \mathrm{kPa}$ $(3 \pm 0.4 \mathrm{mmHg})$ and an exhalation flow of $5-6 \mathrm{~L} \cdot \mathrm{min}^{-1}$. The subjects exhaled slowly from total lung capacity (TLC) over 10-15 s, maintaining a constant flow. The mean of two reproducible measurements with $<5 \%$ variation was recorded. Ambient $\mathrm{CO}$ was recorded before each measurement and subtracted from the mean value obtained during the procedures.

\section{Statistical analysis}

Data is expressed as means \pm SEM. A Mann-Whitney U-test was used to compare the groups and the correlations between variables were calculated by means of the Spearman's rank correlation test. A p $<0.05$ was considered significant.

\section{Results}

\section{Interleukin-6}

Exhaled IL-6 levels were significantly higher in smokers $\left(5.6 \pm 1.4 \mathrm{pg} \cdot \mathrm{mL}^{-1}\right)$ than in control subjects $\left(2.6 \pm 0.2 \mathrm{pg} \cdot \mathrm{mL}^{-1}\right.$; $\mathrm{p}<0.01$ ) (fig. 1a). Differences were found between subjects who smoked $<1$ pack $\cdot$ day $^{-1}\left(4.4 \pm 0.1 \mathrm{pg} \cdot \mathrm{mL}^{-1}\right)$, subjects who smoked 1 pack $\cdot \mathrm{day}^{-1}\left(5.0 \pm 0.4 \mathrm{pg} \cdot \mathrm{mL}^{-1}\right)$, and subjects who smoked $>1$ pack $\cdot$ day $^{-1}\left(7.4 \pm 0.9 \mathrm{pg} \cdot \mathrm{mL}^{-1}\right)$ (fig. $\left.1 \mathrm{~b}\right)$.

IL-6 levels were correlated with the number of cigarettes smoked ( $r=0.9, p<0.0001)$ (fig. 2a), exhaled CO ( $\mathrm{r}=0.6, \mathrm{p}<0.005)$ (fig. 2b), FEV1 (r=-0.5, p<0.05) (fig. 2c) and FVC ( $\mathrm{r}=-0.5$, $\mathrm{p}<0.05)$.

IL-6 was undetectable in the saliva of all subjects studied.

\section{Leukotriene $B_{4}$}

Exhaled $\mathrm{LTB}_{4}$ levels were significantly higher in smokers $\left(9.4 \pm 0.4 \mathrm{pg} \cdot \mathrm{mL}^{-1}\right)$ than in control subjects $\left(6.1 \pm 0.3 \mathrm{pg} \cdot \mathrm{mL}^{-1}\right.$; $\mathrm{p}<0.001$ ) (fig. 3). $\mathrm{LTB}_{4}$ levels were significantly correlated with exhaled IL-6 $(\mathrm{r}=0.5, \mathrm{p}<0.005)$. 

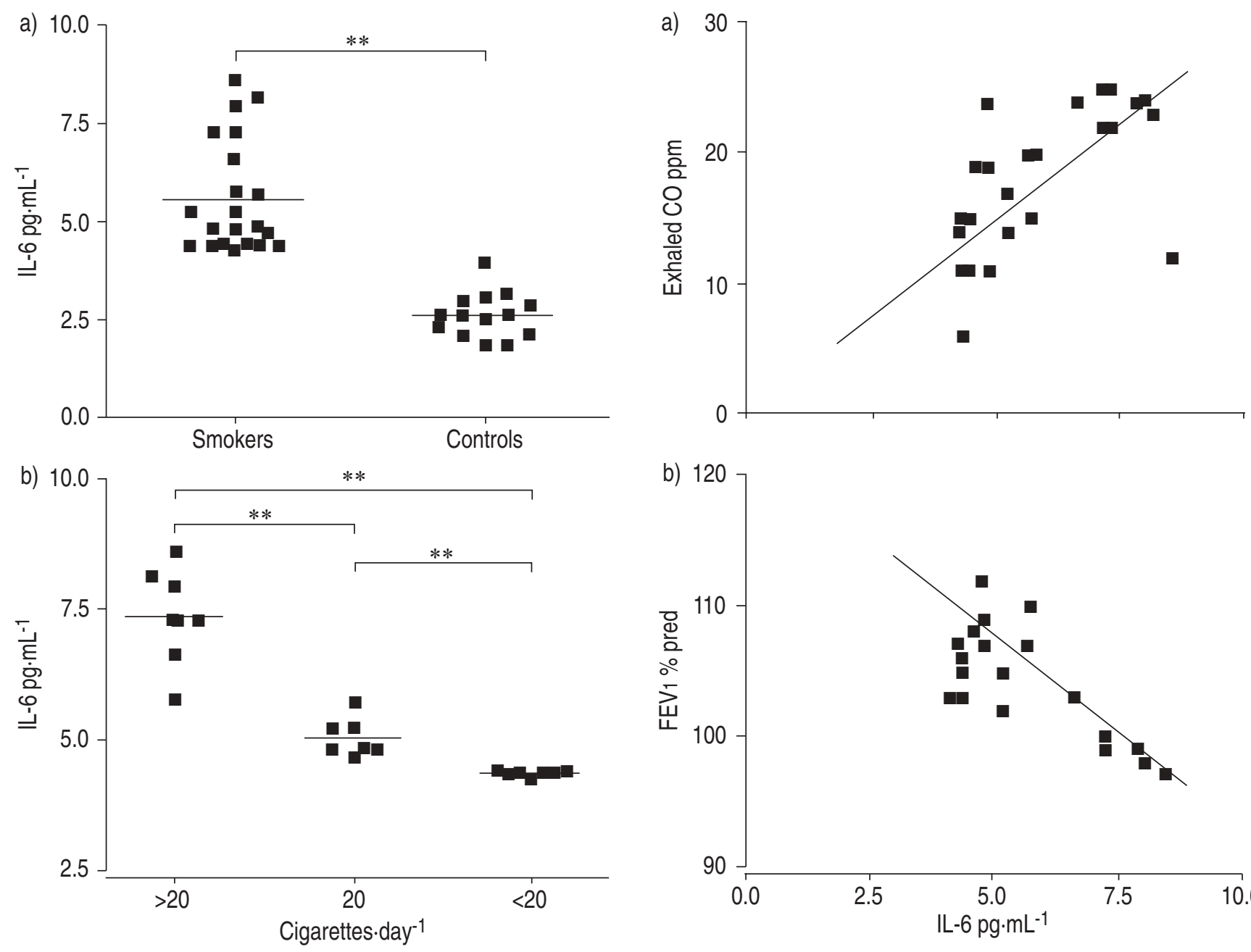

Fig. 1.- Interleukin (IL)-6 concentrations in a) the exhaled breath condensate of cigarette smokers and control subjects and b) the relationship with the amount currently smoked. ${ }^{* *}: \mathrm{p}<0.01$.

\section{Exhaled carbon monoxide}

Exhaled CO was higher in smokers $(16.7 \pm 5.5 \mathrm{ppm})$ than in control subjects (2.1 \pm 0.6 ppm; $\mathrm{p}<0.0001$ (fig. 4)).

\section{Discussion}

This study demonstrated that IL-6 concentrations were increased in the exhaled breath condensate of cigarette smokers and correlated with the number of cigarettes smoked, lung function, and exhaled $\mathrm{LTB}_{4}$ and CO.

Monitoring airway inflammation in smokers may be important as inflammation may play a key role in the pathogenesis of COPD [1]. Noninvasive markers of inflammation may, therefore, be useful in monitoring airway inflammation in smokers and may identify subjects at increased risk of developing airway obstruction [2, 3]. Increased numbers of neutrophils are found in the BAL of smokers and are related to the number of cigarettes smoked and the degree of airflow limitation $[4,10]$. The inflammation of the airways in smokers may also be reflected by increased levels of exhaled $\mathrm{CO}$, which has been extensively used as a noninvasive inflammatory marker. However, this is not a useful marker, due to the high $\mathrm{CO}$ content of cigarette

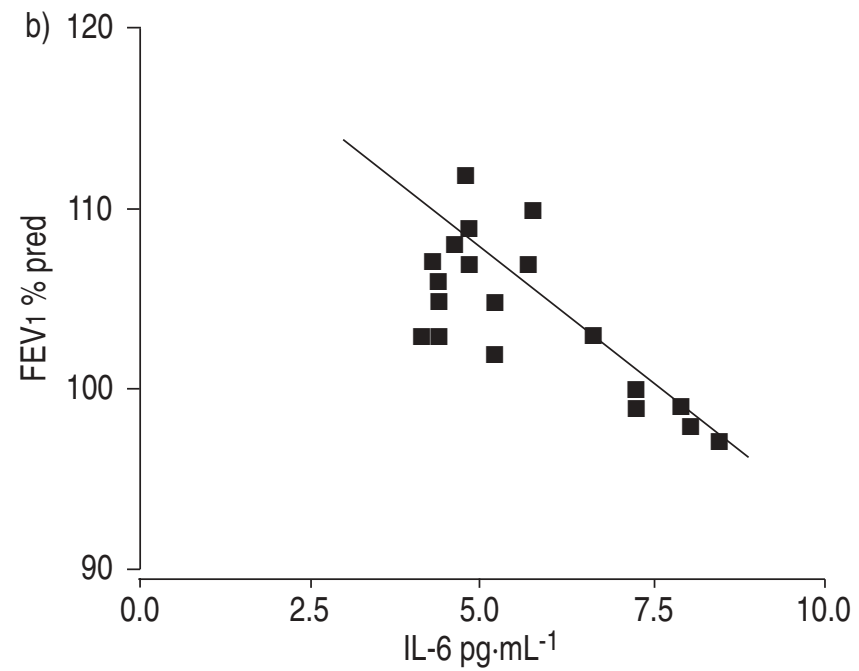

Fig. 2. - Correlation between exhaled interleukin (IL)- 6 concentration and a) exhaled carbon monoxide $(\mathrm{CO})(\mathrm{r}=0.6, \mathrm{p}<0.005)$ and $\mathrm{b})$ per cent predicted forced expiratory volume in one second (FEV1) $(r=0.5$, $\mathrm{p}<0.05)$.

smoke and therefore is likely merely to indicate cigarette smoke [11, 12].

Other inflammatory markers, such as levels of proinflammatory cytokines, for example IL-6 [3, 13-15], IL-8

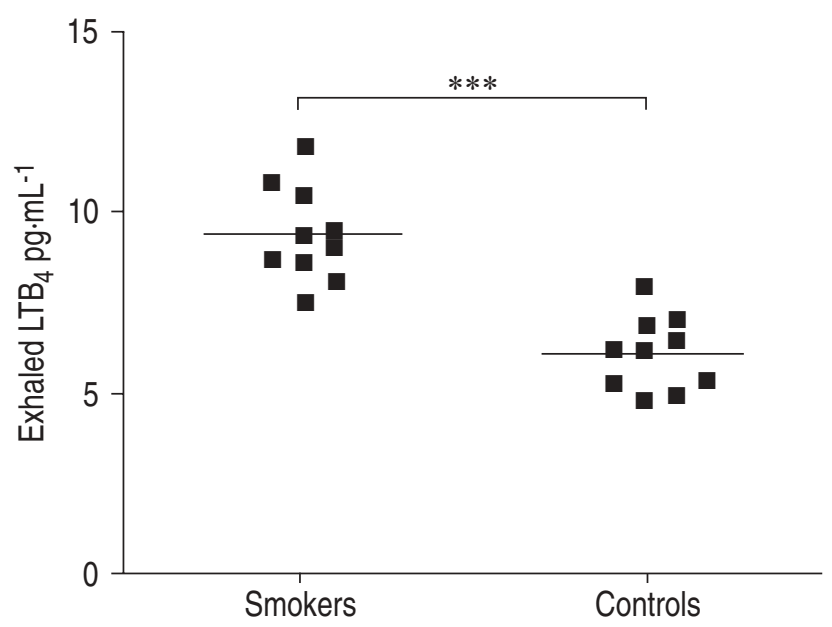

Fig. 3.-Exhaled leukotriene (LT) $\mathrm{B}_{4}$ concentration from cigarette smokers and control subjects. ${ }^{* * *}: \mathrm{p}<0.001$. 


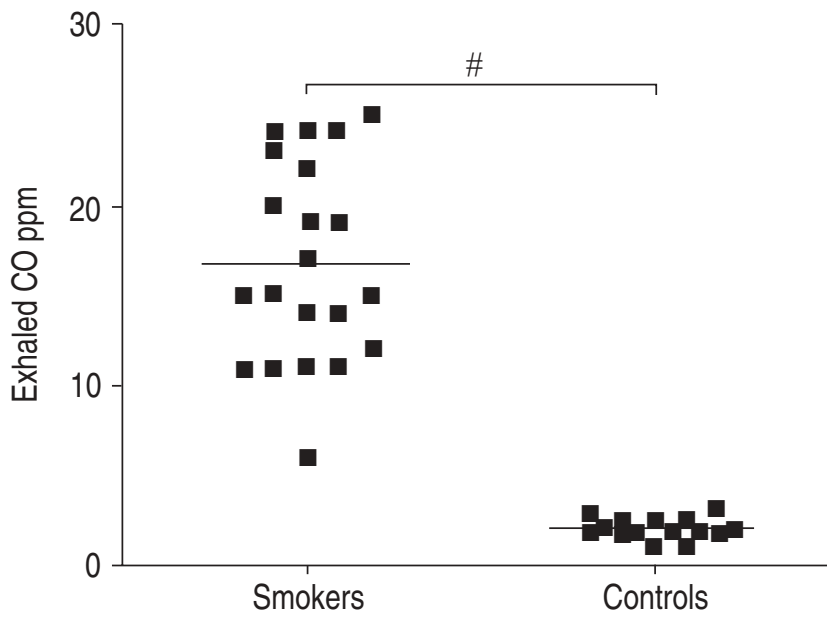

Fig. 4. - Exhaled carbon monoxide (CO) concentration from cigarette smokers and control subjects. ${ }^{\#}$ : $\mathrm{p}<0.0001$.

$[3,13,15]$, IL-1 $\beta[3,14]$ and tumour necrosis factor (TNF)- $\alpha$ $[3,13,14]$, may therefore, be better markers of inflammation. The authors also investigated $\mathrm{LTB}_{4}$ in the breath condensate of smokers, as a marker of neutrophilic inflammation. It was demonstrated that smokers had significantly higher values than normal subjects and this is consistent with the increase in neutrophil numbers in BAL and induced sputum observed by KEATINGS et al. [16]. In agreement with results from the current study, this leukotriene has been found previously to be elevated in sputum [17] and in the BAL of smokers [18].

IL-6 is a pro-inflammatory cytokine involved in the resolution of acute and chronic inflammation, via the induction of glucocorticoid release, as well as via the induction of antagonists of IL-1 $\beta$ and TNF- $\alpha$ [19]. Elevated levels of IL-6 have been reported in the BAL [5, 20], in induced sputum [7], in the blood [7, 21], and in the cervical mucus of smokers [22].

The authors chose to measure IL- 6 levels in exhaled breath condensate of these subjects as they have found that this is the most reliable and reproducible of the pro-inflammatory cytokines. This method allows for the collection of samples that may reflect the composition of the epithelial lining fluid and provides a noninvasive way of monitoring the presence of inflammation and of oxidative stress in the lung [23]. Higher levels of IL-6 in smokers than in control subjects were observed. However, this cytokine was absent in saliva, indicating minimal salivary contamination and that the increase in IL-6 is not a general phenomenon, but confined to the respiratory tract.

The second aim of this study was to investigate the relationship between the intensity of smoking (quantified as a number of cigarettes smoked daily) and exhaled IL-6 concentrations. An increase in the amount of cigarettes smoked was found to be associated with a higher concentration of exhaled IL-6, with a significant correlation between these two variables. KUSCHENER et al. [24] studied several cytokines in the blood in relation to pack-yrs of cigarettes, but found a dose/response only for IL-1 and IL-8. Data from the current study suggests that the intensity of exposure to cigarette smoke is a determinant of exhaled IL- 6 concentration and, therefore, the intensity of airway inflammation.

Increased inflammation of the peripheral airways has been implicated as a cause of airflow limitation in smokers. However, the relationship between subclinical decrements of pulmonary function and inflammation in smokers is still uncertain [25]. It could be possible that the elevated concentrations of IL-6 reflect the loss of laminar flow in smaller airways, favouring aerosolisation of the airway lining fluid.

A negative correlation between exhaled IL-6 concentrations, FEV1 and FVC was observed, thus suggesting that measurement of inflammation may be useful in predicting the early onset of lung function impairment. A positive correlation between this exhaled cytokine, $\mathrm{CO}$ and $\mathrm{LTB}_{4}$ that was expected considering that both these exhaled markers reflect airway inflammation and that might support the authors suggestions, was also found.

In conclusion, results from this study show an increase in exhaled interleukin- 6 that is related to current cigarette-smoke exposure. The measurement of interleukin- 6 and leukotriene $B_{4}$ in the breath condensate may serve as a noninvasive marker, useful in monitoring inflammation of the airways, and the correlation with forced expiratory volume in one second may suggest that it might be an early marker for the development of chronic obstructive pulmonary disease.

\section{References}

1. Hogg JC, Wright JL, Wiggs BR, Coxson HO, Opazo Saez A, Pare PD. Lung structure and function in cigarette smokers. Thorax 1994; 49: 473-478.

2. Barnes PJ. Mechanisms in COPD: differences from asthma. Chest 2000; 117: Suppl. 2, 10-14.

3. Bosken $\mathrm{CH}$, Wiggs BR, Pare PD, Hogg JC. Small airway dimensions in smokers with obstruction to airflow. Am Rev Respir Dis 1990; 142: 563-570.

4. Maestrelli P, Saetta M, Mapp CE, Fabbri LM. Remodelling in response to infection and injury. Airway inflammation and hypersecretion of mucus in smoking subjects with chronic obstructive pulmonary disease. Am J Respir Crit Care Med 2001; 164: Suppl. 10, 76-80.

5. Takeshi M, Sonoko N, Takeo T, et al. Proinflammatory or regulatory cytokines released from BALF macrophages of healthy smokers. Respiration 1999; 66: 419-426.

6. Soliman DM, Twigg HL. Cigarette smoking decreases bioactive interleukin-6 secretion by alveolar macrophages. Am J Physiol 1992; 263: 471-478.

7. Wang $\mathrm{S}, \mathrm{Xu} \mathrm{F}$, Chen $\mathrm{Y}$. Detection and significance of interleukin-8, 6, tumour necrosis factor- $\alpha$ in sputum from patients with chronic obstructive pulmonary disease. Zhonghua Jie He He Hu Xi Zhi 2000; 23: 465-467.

8. Kharitonov SA, Barnes PJ. Exhaled markers of inflammation. Curr Opin Allergy Clin Immunol 2001; 1: 217-224.

9. Hill AT, Bayley DL, Campbell EJ, Hill SL, Stockley RA. Airways inflammation in chronic bronchitis: the effects of smoking and alphal-antitrypsin deficiency. Eur Respir $J$ 2000; 15: 886-890.

10. Barbers RG, Gong H, Tashkin DP, Oishi J, Wallace JM. Differential examination of bronchoalveolar lavage cells in tobacco cigarette and marijuana smokers. Am Rev Respir Dis 1987; 135: 1271-1275.

11. Montuschi P, Kharitonov SA, Barnes PJ. Exhaled carbon monoxide and nitric oxide in COPD. Chest 2001; 120: 496501.

12. Balint B, Donnelly LE, Hanazawa $\mathrm{T}$, Kharitonov SA, Barnes PJ. Increased nitric oxide metabolites in exhaled breath condensate after exposure to tobacco smoke. Thorax 2001; 56: 456-461.

13. McCrea KA, Ensor JE, Nall K, Bleecker ER, Hasday JD. Altered cytokine regulation in the lungs of cigarette smokers. Am J Respir Crit Care Med 1994; 150: 696-703.

14. Sauty A, Manuel J, Philippeaux M, Leuenberg P. Cytostatic activity of alveolar macrophages from smokers and nonsmokers: role of interleukin-1 $\beta$, interleukin- 6 and tumor necrosis factor- $\alpha$. Am J Respir Cell Mol Biol 1994; 11: 631637.

15. Torres A, Utell MJ, Morow PE, et al. Airway inflammation 
in smokers and non-smokers with varying responsiveness to ozone. Am J Respir Crit Care Med 1997; 156: 728-736.

16. Keatings VM, Collins PD, Scott PD, Barnes PJ. Differences in interleukin-8 and tumor necrosis factor-alpha in induced sputum from patients with chronic obstructive pulmonary disease or asthma. Am J Respir Crit Care Med 1996; 156: 530-534.

17. Hill AT, Bayley DL, Campbell EJ, Hill SL, Stockley RA. Airways inflammation in chronic bronchitis: the effects of smoking and alphal-antitrypsin deficiency. Eur Respir $J$ 2000; 15: 886-890.

18. Zijlstra FJ, Vincent JE, Mol WM, Hoogsteden HC, Van Hal PT, Jongejan RC. Eicosanoid levels in bronchoalveolar lavage fluid of young female smokers and non-smokers. Eur J Clin Invest 1992; 22: 301-306.

19. Tilg H, Dinarello CA, Mier JW. IL-6 and APPs: antiinflammatory and immunosuppressive mediators. Immunol Today 1997; 18: 428-432.

20. Soler N, Ewing S, Torres A, Filella X, Gonzales J, Zaubet A. Airway inflammation and bronchial microbial patterns in patients with stable chronic obstructive pulmonary disease. Eur Respir J 1999; 14: 1015-1022.

21. Fernandez-Real JM, Vayreda M, Richard C, Gutierrez C, Broch M, Ricart W. Circulating interleukin 6 levels, blood pressure, and insulin in apparently healthy men and women. $J$ Clin Endocrinol Metab 2001; 86: 1154-1159.

22. Eppel W, Worda C, Frigo P, Manavi M, Czerwenka K. The influence of nicotine on interleukin 6 expression in smokers with cervical preneoplasia. Acta Obstet Gynecol Scand 2000; 79: 1105-1111.

23. Kharitonov SA, Barnes PJ. Exhaled Markers of pulmonary Disease. Am J Respir Crit Care Med 2001; 163: 16931722.

24. Kuschner WG, D'Alessandro A, Wong H, Blanc PD. Dose dependent cigarette smoking-related inflammatory responses in healthy adults. Eur Respir J 1996; 9: 1989-1994.

25. McKarns SC, Smith CJ, Morton MJ, et al. Correlation of hematologic markers of inflammation and lung function: a comparison of asymptomatic smokers and non-smokers. Hum Exp Toxicol 1996; 15: 523-532. 